\title{
Basic physical and mechanical properties of cement composites after temperature exposure
}

\author{
Dana Konakova ${ }^{1}$, Eva Vejmelkova $^{1}$, Lenka Scheinherrova ${ }^{1}$, Martin Keppert $^{1}$, An \\ Cheng $^{2}$, and Robert Cerny ${ }^{1, *}$ \\ ${ }^{1}$ Czech Technical University in Prague, Faculty of Civil Engineering, Department of Materials \\ Engineering and Chemistry, Thákurova 7, 16629 Prague 6, Czech Republic \\ ${ }^{2}$ National Ilan University, Department of Civil Engineering, Shennong Rd., I-Lan 260, Taiwan
}

\begin{abstract}
Basic physical and mechanical properties of several cement composites are determined as functions of thermal load and the results are compared with reference materials. Bulk density, matrix density, and open porosity are measured using the water vacuum saturation method. Compressive and bending strengths are determined according to the European standard. High-temperature coefficient of thermal expansion is obtained using a comparative measurement. Experimental results show that composites based on Portland cement do not resist high temperatures well. Their applicability is limited to $400{ }^{\circ} \mathrm{C}$, due to the damage caused by hydrates decomposition. On the other hand, composites based on calcium aluminate cement exhibit a better thermal stability and retain residual strength even after being exposed to $1000{ }^{\circ} \mathrm{C}$.
\end{abstract}

\section{Introduction}

Building structures can be exposed to extreme conditions during their lifetime. One of these extreme situations is fire, or more precisely, exposure to extreme temperatures. In this case, there is a high likelihood of damage occurring to building materials, which could lead to the final collapse of a whole structure. Thermal loading can cause the chemical and physical modifications of exposed materials. More specifically, material composition alteration as well as thermal strain can occur. These changes are subsequently accompanied by mechanical strength decrease. Therefore, it is important to study not only mechanical properties, but to pay attention mainly to the transformation of material composition and the thermal strain development. In this article several concrete mixtures, varying in the different raw materials, are studied.

\section{Experimental methods}

The phase composition of raw materials was studied by X-ray diffraction (XRD) by means of a "PANalytical X'Pert PRO" from Malvern Panalytical Ltd [1].

\footnotetext{
*Corresponding author: cernyr@fsv.cvut.cz
} 
Simultaneous thermal analysis, consisting of differential scanning calorimetry (DSC) and thermogravimetry (TG), was used for the purpose of better characterization of raw-materials behavior at higher temperatures. Specifically, measurement device "LABSYS EVO DTA/DSC" from SETARAM Inc. [2] was employed.

Vacuum water saturation method [3] was used for measuring the basic physical properties,. specifically bulk density, matrix density and open porosity.

Compressive strength and bending strength were measured according to the ČSN EU standard [4]. Bending strength was measured by using an MTS 100 loading device, while for determination of compressive strength a special loading device EU40 was used.

The measurement of thermal strain depending on temperature was performed by a linear thermal horizontal dilatometer [5, 6, 7]. The device utilizes a comparative method; the real thermal expansion is determined by comparing the analyzed specimen with a standard.

\section{Studied materials}

\subsection{Characterization of raw materials}

Calcium aluminate cement (CAC) Secar 71 (Kerneos Inc.) was selected as the main binder. Portland cement (PC) CEM I 52.5R (Lafarge, a.s. Č́žkovice) was used for the reference composites. The mineralogical composition of used cements (Table 1) was distinctly different. In the case of CAC, the main phases were calcium aluminates, while in the case of PC calcium silicates. The granularity of both cements varied just slightly, CAC was somewhat finer.

Table 1. Mineralogical composition of used cements.

\begin{tabular}{|c|c|c|c|c|c|c|c|}
\hline \multirow{2}{*}{$\mathbf{C A C}$} & $\mathbf{C A}$ & $\mathbf{C A}_{\mathbf{2}}$ & $\mathbf{C}_{\mathbf{1 2}} \mathbf{A}_{\mathbf{7}}$ & $\mathbf{A}$ & $\boldsymbol{\beta}-\mathbf{A l}_{\mathbf{2}} \mathbf{O}_{\mathbf{3}}$ & $\mathbf{C}_{\mathbf{3}} \mathbf{A H}_{\mathbf{6}}$ & Amorphous \\
\cline { 2 - 8 } & 54.7 & 38.1 & 0.5 & 0.8 & 1.4 & 0.6 & 3.9 \\
\hline \multirow{2}{*}{$\mathbf{P C}$} & $\mathbf{C}_{\mathbf{3}} \mathbf{S}$ & $\mathbf{C}_{\mathbf{2}} \mathbf{S}$ & $\mathbf{C}_{\mathbf{4}} \mathbf{A} \mathbf{A}$ & $\mathbf{G y p s u m}$ & Anhydride & Calcite & Quartz \\
\cline { 2 - 8 } & 71.6 & 6.5 & 9.6 & 1.2 & 4.2 & 6.1 & 0.8 \\
\hline
\end{tabular}

Basalt aggregate was chosen for the preparation of thermally resistant composites. Two grades (0/4 and 2/5) of crushed aggregate were obtained from the quarry in Dobkovičky of Kámen Zbraslav, a. s. The aggregate was composed mainly of pyroxenes (specifically, clinopyroxene and augite and in lower amounts diopside), followed by analcime, anorthite, muscovite, and in lower amounts nepheline. However, due to the similar and non-defined composition of pyroxenes and plagioclase (specifically anorthite), precise quantitative analysis from the XRD measurement could not be performed. As in the case of cement, also aggregates were of two kinds. Silica sand was used for the reference material. Specifically, four grades $(0.1 / 0.6,0.3 / 0.8,0.6 / 1.2$ and 1/4) of sand originated in Sklopísek Střeleč a.s. were used in mixture design. This material composed entirely of quartz.

Due to their appropriate properties and assumed good compatibility with other raw materials, basalt fibers were chosen for reinforcing the designed composites, specifically 12.7 $\mathrm{mm}$ long fibers produced by Basaltex, a.s. The diameter of used fibers was $13 \mu \mathrm{m}$ and they were coated with a silane based lubrication $(1-1.5 \%$ by mass $)$.

The remaining components of mixtures were potable water and superplasticizer. The used Sika VsicoCrete®-1035CZ superplasticizer was based on modified polycarboxylateether. 


\subsection{Thermal analysis of raw materials}

The results of thermal analysis are presented in Figures 1 and 2. In the case of Portland cement paste the observed peaks were in accordance with the already well-known processes $[8,9,10]$. The changes observed up to $150{ }^{\circ} \mathrm{C}$ were connected with the loss of free water. In this range, also the dehydration of CSH took place (this process continued up to $400{ }^{\circ} \mathrm{C}$ ). In the range of $100{ }^{\circ} \mathrm{C}$ to $200{ }^{\circ} \mathrm{C}$, sulfoaluminates (ettringite, gypsum and monosulphate) dehydrated and physically bound water was released. The second major peak in the temperature range of $450{ }^{\circ} \mathrm{C}$ to $500{ }^{\circ} \mathrm{C}$ corresponded with the decomposition of portlandite. The last peak of the DSC curve (temperatures from $700{ }^{\circ} \mathrm{C}$ to $800{ }^{\circ} \mathrm{C}$ ) of Portland cement reflected the decomposition of calcium carbonate (in the form of calcite and vaterite).

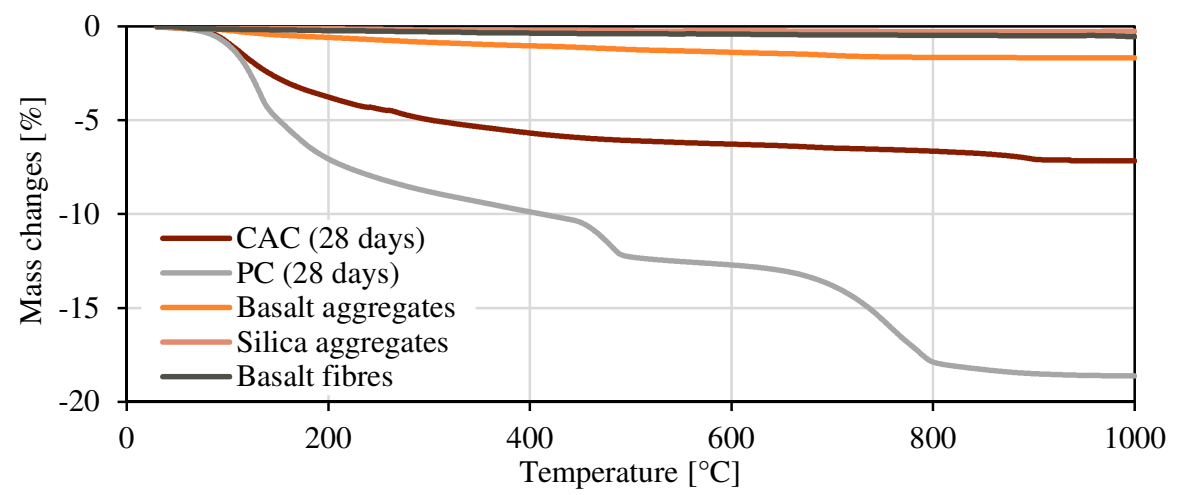

Fig. 1. Thermogravimetry of raw materials.

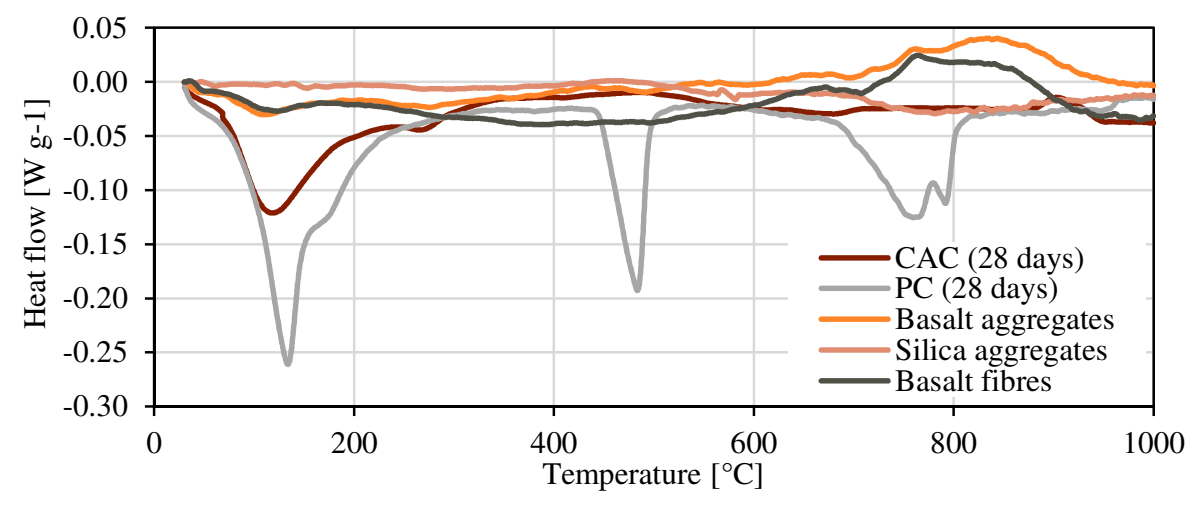

Fig. 2. Differential scanning calorimetry curves of raw materials.

The processes in the CAC paste occurring at the temperatures up to $120^{\circ} \mathrm{C}$ included the loss of free water in capillary pores and bound water in aluminate hydrate gel $\left(\mathrm{AH}_{3}\right)$ [11]. The first endothermic peak at $\sim 120{ }^{\circ} \mathrm{C}$ corresponded with dehydration of calcium aluminate decahydrate $\left(\mathrm{CAH}_{10}\right)$. The decomposition temperature of this hydrate ranged from $100{ }^{\circ} \mathrm{C}$ to $160{ }^{\circ} \mathrm{C}[8,12]$ and in the 28 -days cement paste a loss of $3 \%$ of weight up to the temperature of $160{ }^{\circ} \mathrm{C}$ was observed. There were not found any significant peaks at the decomposition temperatures of the other two major calcium aluminate hydrates $\left(\mathrm{C}_{2} \mathrm{AH}_{8}\right.$ and $\left.\mathrm{C}_{3} \mathrm{AH}_{6}\right)$. Dicalcium aluminate octahydrate $\left(\mathrm{C}_{2} \mathrm{AH}_{8}\right)$ dehydrates between $140{ }^{\circ} \mathrm{C}$ and $240{ }^{\circ} \mathrm{C}[8,11$, $12]$, and its presence could be hidden by the major peak of calcium aluminate decahydrate $\left(\mathrm{CAH}_{10}\right)$ and the multiple one of gibbsite $\left(\mathrm{AH}_{3}, 210{ }^{\circ} \mathrm{C}-320{ }^{\circ} \mathrm{C}[8,11]\right)$ and tricalcium aluminate hexahydrate $\left(\mathrm{C}_{3} \mathrm{AH}_{6}, 240{ }^{\circ} \mathrm{C}-370{ }^{\circ} \mathrm{C}[11,12]\right)$. Gibbsite (crystalline $\left.\mathrm{AH}_{3}\right)$ and 
stable katoite $\left(\mathrm{C}_{3} \mathrm{AH}_{6}\right)$ were not formed during the hydration process in higher amount, but they appeared as a product of the temperature decomposition of thermodynamically unstable hydrates $\left(\mathrm{CAH}_{10}\right.$ and $\left.\mathrm{C}_{2} \mathrm{AH}_{8}\right)$. Katoite $\left(\mathrm{C}_{3} \mathrm{AH}_{6}\right)$ dehydration gave rise to the dodecacalcium heptaaluminate hydrate $\left(\mathrm{C}_{12} \mathrm{AH}_{7}\right)$ that is known to decompose at $\sim 750{ }^{\circ} \mathrm{C}$ [11]. However, according to our results this reaction occurred earlier, at $\sim 690{ }^{\circ} \mathrm{C}$. The dehydrated phase of dodecacalcium heptaaluminate $\left(\mathrm{C}_{12} \mathrm{~A}_{7}\right)$ later, at the temperatures over $900{ }^{\circ} \mathrm{C}$, recrystallized to $\mathrm{CA}$ and $\mathrm{CA}_{2}$.

Regarding the other components, their mass changes were very small, compared with both kinds of cement. The DSC curve of basalt fibers showed a minor endothermal peak at $\sim 400{ }^{\circ} \mathrm{C}$, which was not observed for basalt aggregate. This could be attributed to the removal of organic coating of fibers [13]. At higher temperatures (above $700{ }^{\circ} \mathrm{C}$ ) both basaltic materials showed exothermal peaks which reflected the crystallization of magnesioferrite and hematite, and the subsequent recrystallization of pyroxenes and plagioclase $[13,14]$.

\subsection{Studied mixtures}

The composition of studied mixtures is shown in Table 2. At first, dry components (aggregate and cement) were properly mixed. Then a portion of water containing superplasticizer was added. After a few minutes of additional mixing, fibers were gradually added. Finally, the remaining water was poured in and the fresh mixtures were put into the molds.

Table 2. Mixture composition of studied composites.

\begin{tabular}{|c|c|c|c|c|c|c|c|c|}
\hline Component & PSR & PBR & PSF & PBF & CSR & CBR & CSF & CBF \\
\hline Calcium aluminate cement & - & - & - & - & 900 & 900 & 900 & 900 \\
\hline Portland cement & 900 & 900 & 900 & 900 & - & - & - & - \\
\hline Silica aggregates 01/06 & 275 & - & 275 & - & 275 & - & 275 & - \\
\hline Silica aggregates 03/08 & 55 & - & 55 & - & 55 & - & 55 & - \\
\hline Silica aggregates 06/12 & 165 & - & 165 & - & 165 & - & 165 & - \\
\hline Silica aggregates 10/40 & 605 & - & 605 & - & 605 & - & 605 & - \\
\hline Basalt aggregates 0/4 & - & 880 & - & 880 & - & 880 & - & 880 \\
\hline Basalt aggregates 2/5 & - & 220 & - & 220 & - & 220 & - & 220 \\
\hline Basalt fibers 12 mm & - & - & 14.5 & 14.5 & - & - & 14.5 & 14.5 \\
\hline Superplasticizer & 9 & 9 & 9 & 9 & 9 & 9 & 9 & 9 \\
\hline Water & 225 & 225 & 225 & 225 & 225 & 225 & 225 & 225 \\
\hline
\end{tabular}

Based on the results provided by TG and DSC of raw materials, two temperatures of thermal pre-treatment of cement composites were specified. Specimens for the measurement of basic physical and mechanical properties were either just dried, or loaded by $400{ }^{\circ} \mathrm{C}$ or $100{ }^{\circ} \mathrm{C}$. All specimens were firstly dried in an oven at $105^{\circ} \mathrm{C}$ for 24 hours to evaporate free water from the inner pore structure, Then temperature loading was performed in a furnace with the heating rate of $0.5{ }^{\circ} \mathrm{C}$ per min. After reaching the final temperature $\left(400{ }^{\circ} \mathrm{C}\right.$ or $1000{ }^{\circ} \mathrm{C}$ ), the samples were exposed to that temperature for 3 hours. Cooling was natural and took place in the furnace as well.

\section{Results and discussion}

\subsection{Basic physical properties}

The influence of different cements on the bulk density was in the reference state not very high (Table 3 ); its values varied by about $1 \%$. Regarding the influence of varying aggregates, 
the utilization of basalt led to $7 \%$ higher bulk densities than in the case of silica aggregates. Lower differences could be observed when fibers were employed; the changes in bulk densities were $\sim 3 \%$. As for the thermal stability, the biggest changes caused by the temperature exposure of $1000{ }^{\circ} \mathrm{C}$ could be observed in the case of Portland cement with silica aggregate. In average the decrease of bulk densities of those composites was $\sim 18 \%$. Because of the strongly weakened materials (cement hydration products were seriously deteriorated due to the temperature loading, silica aggregates increased their volume significantly after the quartz transition temperature of $573^{\circ} \mathrm{C}$ and caused crack appearance) the utilization of fibers had no advantageous effect. The best results were obtained for the material composed of calcium aluminate cement, basalt aggregate and basalt fibers. In that case, the change of bulk density was $1 \%$.

The obtained values of matrix density showed that hydration of CAC led to a heavier matrix; the difference was $\sim 8 \%$ compared with the ordinary PC. In the case of varying aggregate, similarly to the bulk densities, composites with basalt aggregate reached $\sim 11 \%$ higher values than composites with silica aggregate. The apparent reason was the higher density of basalt aggregate. The influence of basalt fibers on matrix densities of the composites was minimal; their values varied by less than $1 \%$. Due to the temperature exposure material transformations occurred; e.g., hydrated phases were decomposed and denser anhydrous minerals were formed. Therefore, the residual values of matrix densities increased by $\sim 18 \%$ in average for all studied composites.

The composites based on CAC exhibited, in average, $\sim 37 \%$ higher values of open porosity than the ones with PC. Regarding the influence of used aggregates, higher porosity values were observed for composites containing basalt aggregate; the difference was $\sim 23 \%$. The utilization of fibers had a lowest impact; the open porosity grew up by $\sim 12 \%$. The influence of temperature exposure was obviously the most important. The observed changes were associated with matrix deterioration (formation of denser hydrates) as well as aggregate transformations. The biggest porosity increase could be found in the case of PC and silica aggregates, $\sim 75 \%$ after loading by $1000{ }^{\circ} \mathrm{C}$. When basalt aggregates were used, the growth was $\sim 54 \%$. Composites with calcium aluminate cement changed their open porosities due to the temperature loading by $\sim 46 \%$ in average. The best results were achieved for the composite containing CAC, basalt aggregate, and basalt fibers. The porosity increase after the exposure to $1000{ }^{\circ} \mathrm{C}$ was $37 \%$.

Table 3. Basic physical properties of studied composites.

\begin{tabular}{|c|c|c|c|c|c|c|c|c|c|}
\hline & \multicolumn{3}{|c|}{ Bulk density $\left[\mathrm{kg} \mathrm{m}^{-3}\right]$} & \multicolumn{3}{c|}{ Matrix density $\left[\mathbf{k g ~ m}^{-3}\right]$} & \multicolumn{3}{c|}{ Open porosity [-] } \\
\cline { 2 - 10 } & $105^{\circ} \mathrm{C}$ & $400{ }^{\circ} \mathrm{C}$ & $1000^{\circ} \mathrm{C}$ & $105^{\circ} \mathrm{C}$ & $400{ }^{\circ} \mathrm{C}$ & $1000^{\circ} \mathrm{C}$ & $105^{\circ} \mathrm{C}$ & $400{ }^{\circ} \mathrm{C}$ & $1000^{\circ} \mathrm{C}$ \\
\hline PSR & 2174 & 2158 & 1803 & 2402 & 2674 & 2961 & 0.095 & 0.191 & 0.391 \\
\hline PBR & 2380 & 2365 & 2358 & 2755 & 3087 & 3397 & 0.136 & 0.234 & 0.306 \\
\hline PSF & 2162 & 2136 & 1722 & 2428 & 2690 & 2997 & 0.109 & 0.206 & 0.425 \\
\hline PBF & 2287 & 2258 & 2234 & 2695 & 2995 & 3260 & 0.151 & 0.246 & 0.315 \\
\hline CSR & 2190 & 2099 & 1996 & 2606 & 2800 & 3225 & 0.159 & 0.250 & 0.381 \\
\hline CBR & 2347 & 2326 & 2259 & 2936 & 3217 & 3588 & 0.201 & 0.286 & 0.370 \\
\hline CSF & 2116 & 2068 & 2036 & 2621 & 2794 & 3122 & 0.193 & 0.260 & 0.348 \\
\hline CBF & 2304 & 2300 & 2282 & 2950 & 3198 & 3487 & 0.219 & 0.281 & 0.345 \\
\hline
\end{tabular}

\subsection{Mechanical properties}

In the reference state, the composites based on PC reached higher compressive strengths (Table 4), $\sim 12 \%$ in a comparison with CAC composites. The influence of aggregate was lower; compressive strengths of composites with basalt aggregates were $\sim 7 \%$ higher. The impact of fibers was indisputably positive but its extent depended on the used cement. When 
PC was used, the improvement was $\sim 5 \%$, while in the case of CAC the compressive strength increased by $\sim 10 \%$. The high temperature exposure led to a fall of compressive strength of all composites. The loading by $400{ }^{\circ} \mathrm{C}$ led to a decrease of compressive strengths by $\sim 43 \%$ in average, which was still acceptable. However, after the temperature exposure to $1000{ }^{\circ} \mathrm{C}$ the fall continued up to almost $95 \%$ in the worst case of PC and silica aggregates (regardless the fiber utilization). The decrease of compressive strength was mitigated by the utilization of more thermal resistant raw materials. When silica aggregates was replaced by basalt ones the fall of compressive strength was $83 \%$ (it was caused by the elimination of quartz transformation). Better results were reached by materials based on CAC, where the decrease was less than $80 \%$. The best results showed the basalt fiber reinforced CAC based composite with basalt aggregate where the change due to the temperature loading was less than $60 \%$.

In contrast with the compressive strength, the CAC based composites showed higher bending strength in comparison with PC already in the reference state. The difference was $22 \%$. The influence of basalt aggregate was similar as in the case of compressive strengths. Its application led to bending strengths growth by $\sim 10 \%$. A similar positive effect was observed when the composites were reinforced by basalt fibers; bending strengths were $\sim 6 \%$ higher. The impact of temperature loading on the residual bending strengths was very important. In the case of $400{ }^{\circ} \mathrm{C}$ pre-treatment, the bending strength decrease ranged from $65 \%$ to $48 \%$, which was higher than in the case of compressive strength. For the $1000{ }^{\circ} \mathrm{C}$ loading, the bending strength of PC-based composite with silica aggregate was almost $97 \%$ lower than in the reference state. For the CAC-based material with the same aggregate the decrease was lower but still very substantial, $\sim 89 \%$. The application of basalt aggregate resulted in residual bending strengths $\sim 77 \%$ lower than in the reference state. The combination of basalt aggregate and basalt fibers provided the best outcome, the bending strength of CAC based composite decreased by $\sim 68 \%$.

Table 4. Mechanical properties of studied composites.

\begin{tabular}{|c|c|c|c|c|c|c|}
\hline & \multicolumn{3}{|c|}{ Compressive strength [MPa] } & \multicolumn{3}{c|}{ Bending strength [MPa] } \\
\cline { 2 - 7 } & $105^{\circ} \mathrm{C}$ & $400^{\circ} \mathrm{C}$ & $1000^{\circ} \mathrm{C}$ & $105^{\circ} \mathrm{C}$ & $400{ }^{\circ} \mathrm{C}$ & $1000^{\circ} \mathrm{C}$ \\
\hline PSR & 93.2 & 43.6 & 3.5 & 8.71 & 3.19 & 0.32 \\
\hline PBR & 99.5 & 55.6 & 16.8 & 9.86 & 4.60 & 0.72 \\
\hline PSF & 97.4 & 52.8 & 4.8 & 9.73 & 3.59 & 0.31 \\
\hline PBF & 104.8 & 61.6 & 17.4 & 10.68 & 5.55 & 1.72 \\
\hline CSR & 80.5 & 46.0 & 15.6 & 11.67 & 4.04 & 1.27 \\
\hline CBR & 84.4 & 48.4 & 19.6 & 12.87 & 5.46 & 2.98 \\
\hline CSF & 87.6 & 47.5 & 22.9 & 12.14 & 4.63 & 1.33 \\
\hline CBF & 95.9 & 65.4 & 39.5 & 13.40 & 6.37 & 4.30 \\
\hline
\end{tabular}

\subsection{Thermal strain}

Figure 3 shows that the thermal strain up to $200^{\circ} \mathrm{C}$ was lower for the CAC composites than for the PC ones, $\sim 10 \%$ in average. When temperature exceeded $200{ }^{\circ} \mathrm{C}$, the tendency was reversed and up to $800^{\circ} \mathrm{C} \mathrm{CAC}$ showed $\sim 19 \%$ higher thermal strain. At the temperatures higher than $800^{\circ} \mathrm{C}$ a faster increase of thermal strain of PC composites was observed which was probably caused by vaterite formation. The effect of used aggregate was more important than the type of cement. The difference between the thermal strain of composites with silica and basalt aggregate was $\sim 21 \%$ already at $40{ }^{\circ} \mathrm{C}$ and then increased continuously up to 600 ${ }^{\circ} \mathrm{C}$ to $\sim 72 \%$. The apparent reason was the higher thermal expansion coefficient of silica. The recrystallization of quartz at $573{ }^{\circ} \mathrm{C}$ was then responsible for the steep increase of thermal strain at $\sim 600^{\circ} \mathrm{C}$. The composites with basalt aggregate showed a slow continuous increase of thermal strain without any irregularities. Regarding the impact of basalt fibers, except for the combination of basalt aggregate and PC, the effect of reinforcement was positive and 
thermal strain decreased. In the CAC composites with basalt fibers the fall was 7\%. However, for temperatures higher than $900{ }^{\circ} \mathrm{C}$ a steep growth of thermal strain was observed for the composite containing PC, basalt fibers and silica aggregate, which was an unexpected behavior. Repeated experiments showed that a

random error could be excluded in this case. A possible explanation could be found in a synergetic effect of vaterite decomposition over $800{ }^{\circ} \mathrm{C}$, recrystallization of $\beta$-quartz to $\beta$ tridymite at $870^{\circ} \mathrm{C}$, and softening of basalt fibers at $\sim 950^{\circ} \mathrm{C}$.

Wang et al. [15] analyzed thermal strain of CAC composites up to $1400{ }^{\circ} \mathrm{C}$ and reported a decrease of linear thermal strain at about $300{ }^{\circ} \mathrm{C}$ which was caused by decomposition of tricalcium aluminate hexahydrate $\left(\mathrm{C}_{3} \mathrm{AH}_{6}\right)$. In this study, a slight decrease could be observed earlier, which was caused by the presence of other metastable calcium aluminate hydrates. Hartlieb et al. [16] observed similar effects of aggregates on thermal strain as in this paper; quartz transformation was the most significant, while the use of basalt led to a continuous increase. They also performed consecutive second measurements and found higher thermal strain for all composites, while the residual strain was much greater in the case of silica aggregate.
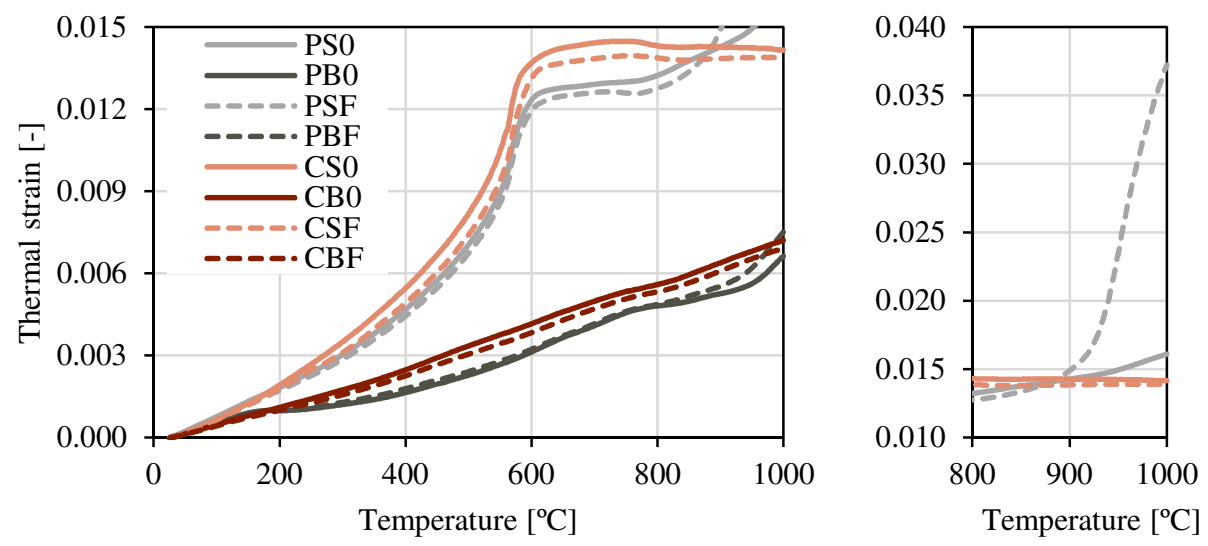

Fig. 3. Thermal strain of studied composites.

It is obvious that the linear thermal expansion coefficient $\alpha$ (which can be calculated as the first derivative of thermal strain) should be as constant as possible for material application at high temperatures. The CAC based composites with basalt aggregate met well this condition; without fiber reinforcement the value of $\alpha$ was $1.4510^{-5} \mathrm{~K}^{-1}$, while when basalt fibers were used it decreased to $7.110^{-6} \mathrm{~K}^{-1}$.

\section{Conclusions}

The measurements of basic physical and mechanical properties of cement composites exposed to elevated temperatures up to $1000{ }^{\circ} \mathrm{C}$ showed that the selection of appropriate raw materials was very important. The substantially lower thermal stability of Portland cement in a comparison with calcium aluminate cement was confirmed; the composites based on Portland cement were found suitable for an application up to $400^{\circ} \mathrm{C}$ only. The effect of applied aggregates was also significant; basalt appeared as a much better alternative to silica. The utilization of basalt fibers led to another substantial improvement. The composites based on the combination of calcium aluminate cement, basalt aggregate and basalt fibers had the highest thermal stability. They retained substantial residual strength even after being exposed 
to $1000{ }^{\circ} \mathrm{C}$. Therefore, they have a good potential to be used as fire-protection materials in building structures.

This research has been supported by the Czech Science Foundation, under Project No. 20-00653S, and by the Grant Agency of the Czech Technical University in Prague, under project No. SGS19/143/OHK1/3T/11.

\section{References}

1. X-ray Diffraction (XRD). Royston, United Kingdom: Malvern Panalytical (2018)

2. Brochure - LABSYS evo. Cranbury Township, New Jersy: SETARAM Instrumentation (2017)

3. S. Roels, J. Carmeliet, H. Hens, O. Adan, H. Brocken, R. Černý, Z. Pavlík, C. Hall, K. Kumaran, L. Pel, R. Plagge, J. Therm. Envel. Build. Sci. 27, 307 (2004)

4. ČSN EN 1015 (2000)

5. J. Toman, A. Trník, A. Krička, Utility model 21752, The Industrial Property Office (IPO CZ, 2011)

6. A. Trník, I. Medved', R. Černý, Cement Lime Concrete, 79, 363 (2012)

7. Dilatometry Řevnice, (CLASIC CZ s.r.o. 2017)

8. C. N. Collier, Ceram-Silikaty, 60, 338 (2016)

9. H. Sauber, G. Platret, J. Vincent, J. Therm. Anal. Calorim., 126, 1023 (2016)

10. Q. Zhang, G. Ye, J. Therm. Anal. Calorim., 110, 153 (2012)

11. M. A. Maaroufi, A. Lecomte, C. Diliberto, O. Francy, P. Brun, J. Eur. Ceram. Soc. 35, 1637 (2015)

12. V. Antonovič, J. Keriene, R. Boris, M. Aleknevičius, Procedia Engineer. 57, 99 (2013)

13. F. Sarasini, J. Tirilló, M. Seghini, Compos. Part. B-Eng. 132, 77 (2018)

14. M. S. Manylov, S.I. Gutnikov, K. V. Pokholok, B. I. Lazoryak, Y. V. Lipatov, Mendeleev Commun. 23, 361, (2016)

15. Y. Wang, Y. Li, B. Zhu, P. Chen, Ceram. Int. 42, 11355 (2016)

16. P. Hartlieb, M. Toifl, F. Kuchar, R. Meisels, T. Antretter, Mater. Eng. 91, 34 (2016) 